\title{
Role of Diffusion Weighted MRI in Diagnosis of Breast Masses (BIRADS III and BIRADS IV)
}

\author{
MOUNIR S. GUIRGUIS, M.D.; ALI H.A. NOUR EL DEEN, M.D. and \\ SHIMAA MAGHAWRY EL SAYED, M.Sc.
}

The Department of Radiodiagnosis, Faculty of Medicine, Ain Shams University

\begin{abstract}
Background: The majority of the lesions that occur in the breast are benign, benign lesions of the breast are more frequent than malignant ones. It is important to recognize benign lesions and distinguish them from breast cancer. Breast cancer is most prevalent and is the leading cause of cancer related deaths among women worldwide.

Aim of the Study: To investigate the role of MR diffusion - weighted images as a complementary tool in evaluation of probably benign (BI-RADS-3) and suspicious (BI-RADS-4) breast lesions and its contribution to patient management.

Patients and Methods: The current study included 30 patients with BIRADS3 and 4 breast lesions detected by breast ultrasound and mammography; their mean age was 41 years $( \pm 8.42)$ (age range, 30-70 years). All patients presented with a breast lump, four patients presented with inflammatory manifestations (red with hot tender swollen breast). The study was conducted in Ain Shams University Hospital during the period from December 2019 to March 2021. Cases were referred from General Surgery Departments in Ain Shams University Hospital. The patients underwent full history taking and clinical examination followed by ultrasound and mammographic examination, those patients cases categorized on ultrasound and mammographic as BI-RADS 3 and 4 were selected for DCE-MRI examination.

Results: In this study, it was found that for mass lesions type I curve was found in 10 pathologically proven benign lesions, type III curve was found in 11 pathologically proven malignant lesions compared to 2 pathologically proven benign lesions, and type II curve was present in 1 benign lesion compared to 8 malignant lesions. Our findings for mass lesions showed that malignancies exhibit lower mean ADC values compared with benign lesions. In our study we calculated the ADC value with high $b$-values (600 and 1500) to avoid the signal attenuation caused by perfusion effects at low $b$-values.

Conclusion: Use of DWI as a diagnostic tool can increase the specificity of breast MR imaging and can reduce the number of false-positive results and associated unnecessary biopsies. In addition, DWI can be performed without significantly increasing examination time.
\end{abstract}

Correspondence to: Dr. Shimaa Maghawry El Sayed, E-Mail: shaimaamaghawry2017@yahoo.com
Key Words: Diffusion Weighted MRI - Breast Masses (BIRADS III and BIRADS IV).

\section{Introduction}

THE majority of the lesions that occur in the breast are benign, benign lesions of the breast are more frequent than malignant ones. It is important to recognize benign lesions and distinguish them from breast cancer [1] .

Breast cancer is the most common cancer diagnosed and is the second leading cause of death [2] breast cancer is now a significant cause of worldwide morbidity and mortality. Further, the increasing rate of breast cancer continues to be a major area of concern for both clinicians and researchers. Increased awareness in the affected population leads to more frequent physical examinations and diagnostic imaging procedures which results in earlier diagnosis and hence improved prognosis [3].

Nowadays sonomammography still represents the primary imaging modality utilized for breast cancer screening and diagnosis [4]. Mammography has been proven to detect breast cancer at an early stage; other screening technologies also may contribute to the earlier detection of breast cancer, particularly in women under the age of 40 years for whom mammography is less sensitive such as breast ultrasound or MRI [5].

Breast ultrasound examination has been used for years as an adjunct to mammography for evaluating palpable or mammographically detected breast masses to determine if a lesion represents a cyst or a solid mass [6]

The Breast Imaging Reporting and Data System (BI-RADS) lexicon was developed by the American Collage of Radiology (ACR) to standardize mam- 
mographic reporting. The lexicon includes terms describing breast parenchymal pattern, features of masses and calcifications. It increases clarity of reporting, improved communication and facilitates research across different institutions [7].

The lexicon defines assessment categories to describe the radiologist's level of suspicion regarding the mammographic findings. BI-RADS-3 is a probably benign finding with short term followup is recommended, while BI-RADS-4 is a suspicious finding and biopsy should be considered [7]

Short term follow-up for a probably benign lesion (BI-RADS-3) has several advantages over biopsy. It is non-invasive, less expensive and it causes less anxiety to the patient. Subsequent malignancy is found in $0.2-2 \%$ of probably benign lesions [8]

Breast MRI has become an important tool for breast cancer detection and characterization. Contrast enhanced MRI (CE-MRI) is currently the most sensitive detection technique for diagnosis of breast cancer [2], dynamic contrast-enhanced MRI is highly sensitive for breast cancer, allowing detection of malignancy that is occult on physical examination, mammography, and sonography [9]

Typical breast MRI exams involve a contrastenhanced scan to highlight tissue with increased vascularity, very sensitive for detecting malignancies but also producing many false-positives [10]

Diffusion Weighted imaging provides microstructural informtions regarding the diffusion of the water molecules in the tissue cellularity and tissue structure by using the quantitative analysis with the apparent diffusion coefficient (ADC) values [11].

Diffusion imaging (DI) is a different type of MRI that measures the mobility of water in tissue. Diffusion imaging is sensitive to characteristics often disrupted in malignant breast tissues, such as cell organization, density, extracellular space, and cell membrane permeability, which may help to better discriminate between different types of breast lesions [10].

Using Diffusion-weighted imaging (DWI) combined to MRI is helpful to distinguish malignant versus benign breast lesions and it also may reduce the number of unnecessary breast biopsies [12]

\section{Aim of the work:}

To investigate the role of MR diffusion - weighted images as a complementary tool in evaluation of probably benign (BI-RADS-3) and suspicious
(BI-RADS-4) breast lesions and its contribution to patient management.

\section{Patients and Methods}

This study is a prospective descriptive study that included 30 patients with BIRADS3 and 4 breast lesions detected by breast ultrasound and mammography; their mean age was 41 years $( \pm 8.42)$ (age range, $30-70$ years). All patients presented with breast lump, four patients presented by inflammatory manifestations (red hot tender swollen breast).

The study was conducted in Ain Shams University Hospital during the period from December 2019 to March 2021. Cases were referred from General Surgery Departments in Ain Shams University Hospital. The patients underwent full history taking and clinical examination, ultrasound and mammographic examination, those patients cases categorized on ultrasound and mammographic as BI-RADS 3 and 4 were selected for DCE-MRI examination.

\section{Ethical considerations:}

- Obtaining an informed consent.

- Risks and complications: MRI scans are considered to be a safe procedure. Side effects or reactions are uncommon but may occur. The most common adverse reactions are brief headache, nausea and dizziness for a brief time following the contrast injection. Anaphylactic reactions to gadolinium contrast medium (CM) but they are extremely rare if concomitant contrast enhanced MRI is executed.

- Treatment in cases of risks and complications: Bed rest after the procedure for management of headache and nausea, analgesia.

Inclusion criteria: The criteria for selecting a patient in the current study are presence of: Incidental breast mass discovered in MRI breast protocol, previously diagnosed indeterminate breast mass via another radiological investigation whether mammography and ultrasound, breast lump that is evident clinically with or without breast pain/ discharge/nipple abnormalities or skin discoloration, only female patients will be included, no age predilection.

\section{Exclusion criteria:}

- Breast biopsy or neo adjuvant chemotherapy before MRI.

- Lesions with a diameter $<1 \mathrm{~cm}$ because of limited capability of recognizing smaller lesions in the ADC maps. 
- Claustrophobia.

- Metallic implants, cardiac pace maker, aneurysmal clipping.

Ultrasound was performed for all patients. The study was conducted on device high frequency probe (5 to $7.5 \mathrm{MHZ}$ ), scanning was done in all planes (radial, antiradial, longitudinal and transverse). Ultrasound and mammographic examinations were analyzed regarding the presence of masses, masses were evaluated regardinging: Their shape, orientation, margins, echopattern (hypoechoic, isoechoic, mixed echogenicity, and hyperechoic), and presence or absence of acoustic shadowing or enhancement. Classification of breast lesions was based on the Breast Imaging Reporting and Data System (BI-RADS). Then all patients with BIRADS 3 and 4 were referred for further DCE-MRI and DWI examination.

\section{Image post processing on the workstation:}

Diffusion maps were formed. A noise-level threshold of 200 was applied to mask the $b=0$ $\mathrm{s} / \mathrm{mm}^{2}$ images before forming diffusion maps. ADC maps were obtained from the diffusion weighted images by

$$
\mathrm{ADC}=-\frac{1}{\mathrm{~b}} \ln \left(\frac{\mathrm{S}_{\mathrm{DWI}}}{\mathrm{S}_{\mathrm{o}}}\right)
$$

where $\mathrm{s}_{\text {DWI }}$ is the combined DWI (geometric average of individual $b=300,600$ or $1500 \mathrm{~s} / \mathrm{mm}^{2}$ diffusion-weighted images), and S0 is the $b=0$ $\mathrm{s} / \mathrm{mm}^{2}$ reference image. An ROI was defined for each DCE-MRI-detected lesion at the corresponding location on the combined DWI ( $\mathrm{S}_{\mathrm{DWI}}$ ) series. The mean ADC of the voxels in the ROI was calculated for each lesion. Quantitative analysis was done by placing the ROI at the most enhanced part within the lesion result in automatically created time/signal intensity curve.

\section{MRI image interpretation:}

Subtraction images were first examined to detect the presence or absence of lesion enhancement. In case of lesion enhancement the corresponding non subtracted pre-contrast and post contrast images in each time point was viewed together and lesions interpretation took place whether it a focus, mass or non mass like enhancement.

In case of mass enhancement evaluation was carried out as follow: its shape (regular or irregular), its border (well defined, ill defined, speculated), pattern of enhancement (homogenous, heterogeneous or ring enhancement), dynamic behavior of the mass with evaluation of the \% of enhancement as well as the shape of time/signal intensity curve (type I, type II or type III) was studied, in case of non mass like enhancement, its distribution and enhancement pattern were evaluated. Diffusion weighted images and ADC maps are then examined regarding the signal intensity and the mean ADC of each lesion. MRI BIRADS classification was applied for each lesion based on the combination of morphologic and kinetic criteria described by Kuhl [13]. Findings were correlated with histopathological result.

\section{Data analysis:}

Data were statistically described in terms of range, mean \pm standard deviation ( $\pm \mathrm{SD}$ ), frequencies (number of cases) and percentages when appropriate. Accuracy was represented using the terms sensitivity and specificity. All statistical calculations were done using computer programs Microsoft Excel 2003 (Microsoft Corporation, NY, and USA) and SPSS (Statistical Package for the Social Science; SPSS Inc., Chicago, IL, USA) version 15 for Microsoft Windows.

\section{Results}

The present study included 30 female patients, their ages ranging from 30 to 70 years with mean age of $41.47 \pm 8.42,13$ lesions were benign and 17 lesions were malignant (Table 1).

Table (1): Shows the mean and standard deviation of the patient's age.

\begin{tabular}{cl}
\hline & Total no. $=30$ \\
\hline Age (years): & \\
Mean \pm SD & $41.47 \pm 8.42$ \\
Range & $30-70$ \\
\hline
\end{tabular}

The present study included 30 patients, their ages ranging from 30 to 70 years with mean age of $41.47 \pm 8.42,13$ lesions were benign and 17 lesions were malignant (Table 2).

Table (2): Shows the mean, standard deviation and range of the patient's age in benign and malignant breast lesions.

\begin{tabular}{llllll}
\hline Age (years) & $\begin{array}{c}\text { Benign } \\
\text { No. }=13\end{array}$ & $\begin{array}{l}\text { Malignant } \\
\text { No. }=17\end{array}$ & $\begin{array}{c}\text { Test } \\
\text { value }\end{array}$ & $\begin{array}{c}p \text { - } \\
\text { value }\end{array}$ & Sig. \\
\hline $\begin{array}{l}\text { Mean } \pm \text { SD } \\
\text { Range }\end{array}$ & $\begin{array}{l}38.08 \pm 5.09 \\
35-54\end{array}$ & $\begin{array}{l}44.06 \pm 9.62 \\
30-70\end{array}$ & $-2.030 \bullet$ & 0.052 & NS \\
\hline
\end{tabular}

$p$-value $>0.05$ : Non significant. $p$-value $<0.01$ : Highly significant. $p$-value <0.05: Significant. $\quad \bullet$ : Independent $t$-test.

Ultrasound and mammography were the first examination performed for all patients for evaluation of the breast lesions, two patients were clas- 
sified only by US and MRI examinations because they were young.

The US and mammography characteristics of the breast lesions in relation to the histopathology results are shown in Tables $(3,4)$.

Table (3): Shows the site and size of the breast lesions in correlation with the histopathology results.

\begin{tabular}{llllll}
\hline \multirow{2}{*}{$\begin{array}{l}\text { Ultrasound } \\
\text { characteristics and } \\
\text { mammography }\end{array}$} & $\begin{array}{c}\text { Histopathology } \\
\text { Benign } \\
\text { No.=13 }\end{array}$ & $\begin{array}{c}\text { Malignant } \\
\text { No.=17 }\end{array}$ & $\begin{array}{c}\text { Test } \\
\text { value }\end{array}$ & $\begin{array}{c}p \text { - } \\
\text { value }\end{array}$ & Sig. \\
\cline { 2 - 3 } $\begin{array}{l}\text { Site: } \\
\text { Right }\end{array}$ & $5(38.5 \%)$ & $7(41.2 \%)$ & $0.023 *$ & 0.880 & NS \\
Left & $8(61.5 \%)$ & $10(58.8 \%)$ & & & \\
Size $(\mathrm{cm}):$ & & & & & \\
Mean \pm SD & $1.96 \pm 0.80$ & $1.99 \pm 0.98$ & $-0.080 \bullet$ & 0.937 & NS \\
Range & $0.5-3$ & $0.8-5$ & & & \\
\hline
\end{tabular}

Table (4): Shows the echogenicity, shape, margin and density of the breast lesions in correlation with the histopathology results.

\begin{tabular}{|c|c|c|c|c|c|}
\hline \multirow{2}{*}{$\begin{array}{l}\text { Ultrasound } \\
\text { characteristics and } \\
\text { mammography }\end{array}$} & \multicolumn{2}{|c|}{ Histopathology } & \multirow{2}{*}{$\begin{array}{c}\text { Test } \\
\text { value }\end{array}$} & \multirow[b]{2}{*}{$\begin{array}{c}p- \\
\text { value }\end{array}$} & \multirow[b]{2}{*}{ Sig. } \\
\hline & $\begin{array}{l}\text { Benign } \\
\text { No. }=13\end{array}$ & $\begin{array}{c}\text { Malignant } \\
\text { No. }=17\end{array}$ & & & \\
\hline \multicolumn{6}{|l|}{ Echogenicity: } \\
\hline Hypoechoic & $7(53.8 \%)$ & $7(53.8 \%)$ & $9.808 *$ & 0.020 & $S$ \\
\hline Isoechoic & $2(15.4 \%)$ & $2(15.4 \%)$ & & & \\
\hline Mixed echogenicity & $3(23.1 \%)$ & $3(23.1 \%)$ & & & \\
\hline Heterogenous & $1(7.7 \%)$ & $1(7.7 \%)$ & & & \\
\hline \multicolumn{6}{|l|}{ Shape and margin: } \\
\hline Rounded & $3(23.1 \%)$ & $3(23.1 \%)$ & $0.151 *$ & 0.698 & NS \\
\hline Oval & $7(53.8 \%)$ & $7(53.8 \%)$ & $11.940 *$ & 0.001 & HS \\
\hline $\begin{array}{l}\text { Ill defined lesion } \\
\text { with Irregular } \\
\text { margin }\end{array}$ & $0(0.0 \%)$ & $0(0.0 \%)$ & $4.588 *$ & 0.032 & $S$ \\
\hline Ill defined lesion & $0(0.0 \%)$ & $0(0.0 \%)$ & $4.588^{*}$ & 0.032 & S \\
\hline $\begin{array}{l}\text { with speculated } \\
\text { margin }\end{array}$ & $2(15.4 \%)$ & $2(15.4 \%)$ & $0.739 *$ & 0.390 & NS \\
\hline $\begin{array}{l}\text { Oval with macro- } \\
\text { lobulated margin } \\
\text { Ill defined lump }\end{array}$ & $1(7.7 \%)$ & $1(7.7 \%)$ & $0.039 *$ & 0.843 & NS \\
\hline \multicolumn{6}{|l|}{ Density: } \\
\hline Hyper dense & $8(66.7 \%)$ & $8(66.7 \%)$ & $4.952 *$ & 0.084 & NS \\
\hline $\begin{array}{l}\text { Hypo and hyper } \\
\text { density }\end{array}$ & $3(25.0 \%)$ & $3(25.0 \%)$ & & & \\
\hline ISO dense & $1(8.3 \%)$ & $1(8.3 \%)$ & & & \\
\hline
\end{tabular}

There were 4 breast lesions associated with edema and one breast lesion associated with nipple retraction, 25 breast lesions were not associated with secondary sign.

There were 2 breast lesions associated with microcalcification (Tables 5,6).
Table (5): Shows the breast lesions which were associated with secondary sign and microcalcification or not.

\begin{tabular}{llllll}
\hline $\begin{array}{l}\text { Ultrasound } \\
\text { characteristics and } \\
\text { mammography }\end{array}$ & $\begin{array}{c}\text { Henign } \\
\text { No.=13 }\end{array}$ & $\begin{array}{c}\text { Malignant } \\
\text { No.=17 }\end{array}$ & $\begin{array}{c}\text { Test } \\
\text { value }\end{array}$ & $\begin{array}{c}p \text { - } \\
\text { value }\end{array}$ & Sig. \\
\cline { 2 - 3 } $\begin{array}{l}\text { 2ry sign: } \\
\text { No }\end{array}$ & $11(84.6 \%)$ & $14(82.4 \%)$ & $0.842 *$ & 0.657 & NS \\
Edema & $2(15.4 \%)$ & $2(11.8 \%)$ & & & \\
Nipple retraction & $0(0.0 \%)$ & $1(5.9 \%)$ & & & \\
Ca: & & & & & \\
No & $13(100.0 \%)$ & $15(88.2 \%)$ & $1.639 *$ & 0.201 & NS \\
Micro-calcification & $0(0.0 \%)$ & $2(11.8 \%)$ & & & \\
\hline
\end{tabular}

Table (6): Shows the ultrasound and mammography BIRADS classification of the breast lesions in comparison to the histopathology.

\begin{tabular}{|c|c|c|c|c|c|}
\hline \multirow{2}{*}{$\begin{array}{l}\text { Ultrasound } \\
\text { characteristics and } \\
\text { mammography }\end{array}$} & \multicolumn{2}{|c|}{ Histopathology } & \multirow{2}{*}{$\begin{array}{c}\text { Test } \\
\text { value }\end{array}$} & \multirow[b]{2}{*}{$\begin{array}{c}p- \\
\text { value }\end{array}$} & \multirow[b]{2}{*}{ Sig. } \\
\hline & $\begin{array}{l}\text { Benign } \\
\text { No. }=13\end{array}$ & $\begin{array}{c}\text { Malignant } \\
\text { No. }=17\end{array}$ & & & \\
\hline \multicolumn{6}{|l|}{ BIRADS: } \\
\hline III & $11(84.6 \%)$ & $3(17.6 \%)$ & $13.274^{*}$ & 0.000 & HS \\
\hline IV & $2(15.4 \%)$ & $14(82.4 \%)$ & & & \\
\hline
\end{tabular}

All patients were referred for MRI examination, the detected breast lesions were classified according to MRI scoring system based on combination of morphological and kinetic criteria.

There were 2 breast lesions exhibits washout curve pattern, 1 breast lesions shows plateu curve pattern and 10 breast lesions show rising curve pattern.

There were 28 breast lesions presented mass enhancement and 2 breast lesions presented as no mass enhancement. One of them presents heterogeneous enhancement and the other presents heterogenous with peripheral enhancement (Table 7).

Table (7): Table shows the signal intensity pattern of enhancement and time/signal intensity curve.

\begin{tabular}{|c|c|c|c|c|c|}
\hline \multirow{2}{*}{ MRI } & \multicolumn{2}{|c|}{ Histopathology } & \multirow{2}{*}{$\begin{array}{c}\text { Test } \\
\text { value }\end{array}$} & \multirow{2}{*}{$\begin{array}{c}p- \\
\text { value }\end{array}$} & \multirow{2}{*}{ Sig. } \\
\hline & $\begin{array}{l}\text { Benign } \\
\text { No. }=13\end{array}$ & $\begin{array}{l}\text { Malignant } \\
\text { No. }=17\end{array}$ & & & \\
\hline \multicolumn{6}{|l|}{ Curve: } \\
\hline Washout & $2(15.4 \%)$ & $9(52.9 \%)$ & $19.716^{*}$ & 0.000 & HS \\
\hline Plateu & $1(7.7 \%)$ & $8(47.1 \%)$ & & & \\
\hline Rising & $10(76.9 \%)$ & $0(0.0 \%)$ & & & \\
\hline \multicolumn{6}{|l|}{$\begin{array}{l}\text { Pattern of } \\
\text { enhancement: }\end{array}$} \\
\hline Homogenous & $7(53.8 \%)$ & $10(58.8 \%)$ & $5.765^{*}$ & 0.217 & NS \\
\hline Heterogenous & $0(0.0 \%)$ & $4(23.5 \%)$ & & & \\
\hline Marginal & $4(30.8 \%)$ & $2(11.8 \%)$ & & & \\
\hline Peripheral & $1(7.7 \%)$ & $1(5.9 \%)$ & & & \\
\hline $\begin{array}{l}\text { Heterogenous + } \\
\text { peripheral (non } 1\end{array}$ & $\begin{array}{l}1(7.7 \%) \\
\text { mass) }\end{array}$ & $0(0.0 \%)$ & & & \\
\hline
\end{tabular}


The diffusion criteria of the breast lesions were assessed and ADC value are measured by means of computer manipulated region of interest (ROI) for the breast lesions (Tables 8-15).

Table (8): Shows the characteristics of the breast lesions on DW images as well as the mean, range and standard deviation of the ADC values in benign and malignant breast lesions.

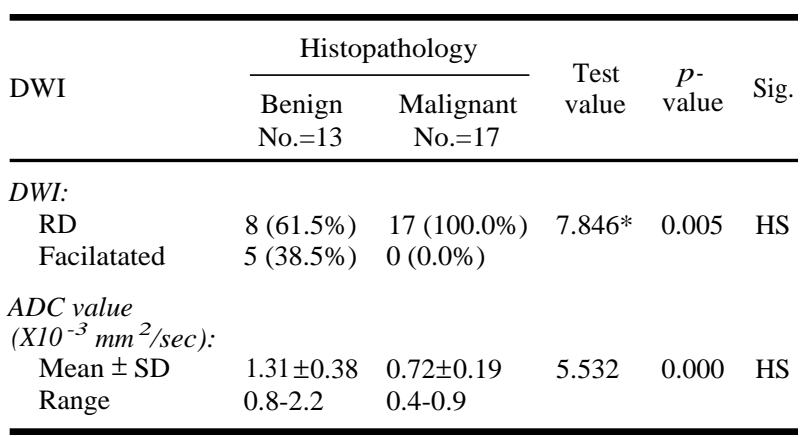

Table (9): Shows the MRI BIRADS classification of the breast lesions in correlation with histopathology.

\begin{tabular}{lllllll}
\hline & \multicolumn{2}{c}{ Histopathology } & & Test \\
MRI & $\begin{array}{c}\text { Benign } \\
\text { No.=13 }\end{array}$ & $\begin{array}{c}\text { Malignant } \\
\text { No.=17 }\end{array}$ & $\begin{array}{c}p- \\
\text { value }\end{array}$ & Sig. \\
& & & & & \\
\hline BIRADS: & & & & \\
II & $2(15.4 \%)$ & $0(0.0 \%)$ & $22.760 *$ & 0.000 & HS \\
III & $9(69.2 \%)$ & $0(0.0 \%)$ & & & \\
IV & $2(15.4 \%)$ & $16(94.1 \%)$ & & & \\
V & $0(0.0 \%)$ & $1(5.9 \%)$ & & & \\
\hline
\end{tabular}

$p$-value $>0.05$ : Non significant. $p$-value $<0.01$ : Highly significant. $p$-value <0.05: Significant. *: Chi-square test. $\bullet$ : Independent $t$-test.

There was statistically significant difference between ADC values regarding age of the patients while there was non statistically significant difference regarding the size of the lesions (Table 10).

Table (10): Correlation between age and size of the breast lesions to the ADC values.

\begin{tabular}{clc}
\hline & \multicolumn{2}{c}{ ADC value $\left(\times 10^{-3} \mathrm{~mm}^{2} / \mathrm{sec}\right)$} \\
\cline { 2 - 3 } & \multicolumn{1}{c}{$r$} & $p$-value \\
\hline Age (years) & $-0.476^{* *}$ & 0.008 \\
Size (cm) & -0.170 & 0.368 \\
\hline
\end{tabular}

$p$-value $>0.05$ : Non significant. $\quad p$-value $<0.01$ : Highly significant. $p$-value $<0.05$ : Significant. Spearman correlation coefficient.

There were 24 hypoechoic lesions with ADC values range $(0.4-1.6)\left(\times 10^{-3} \mathrm{~mm}^{2} / \mathrm{sec}\right), 2$ isoechoic lesions with ADC values range (0.4-1.4) $\left(\times 10^{-3}\right.$ $\left.\mathrm{mm}^{2} / \mathrm{sec}\right), 3$ mixed echogencity with ADC values range (0.9-0.9) $\left(\mathrm{x}_{10}^{-3} \mathrm{~mm}^{2} / \mathrm{sec}\right)$ and 1 hetergenous echogenicity with ADC values range (2.2-2.2) (Table 11).

Table (11): Shows the echogenicity of the breast lesions in relation to the ADC values.

\begin{tabular}{llllll}
\hline & $\begin{array}{c}\text { ADC value } \\
\left(\mathrm{x} 10^{-3} \mathrm{~mm}^{2} / \mathrm{sec}\right)\end{array}$ & $\begin{array}{c}\text { Test } \\
\text { value }\end{array}$ & $\begin{array}{c}p- \\
\text { value }\end{array}$ & Sig. \\
\cline { 2 - 3 } & Mean $\pm \mathrm{SD}$ & Range & & & \\
\hline Echogenicity: & & & & & \\
Hypoechoic & $0.9 \pm 0.35$ & $0.4-1.6$ & $6.233 \bullet \bullet$ & 0.002 & $\mathrm{HS}$ \\
Isoechoic & $1.4 \pm 0$ & $1.4-1.4$ & & & \\
Mixed echogenicity & $0.9 \pm 0$ & $0.9-0.9$ & & & \\
Heterogenous & $2.2 \pm 0$ & $2.2-2.2$ & & & \\
\hline
\end{tabular}

There were 8 rounded lesions with ADC values range 0.8-2.2 and 7 oval lesions with ADC values range 0.9-1.5 and 5 ill defined lesions with irregular margins with ADC values range 0.8-0.8 and 5 ill defined lesions with speculated margins with ADC values range $0.4-0.8,3$ oval with macro-lobulated margins with ADC values range 0.8-1.4 and 1 ill defined lump with ADC values range 0.8-0.8 ( $\mathrm{x}$ $10^{-3} \mathrm{~mm}^{2} / \mathrm{sec}$ ) (Table 12).

Table (12): Shows the shape and margin of breast lesion in relation to the ADC values.

\begin{tabular}{|c|c|c|c|c|c|}
\hline & \multicolumn{2}{|c|}{$\begin{array}{c}\text { ADC value } \\
\left(\times 10^{-3} \mathrm{~mm}^{2} / \mathrm{sec}\right)\end{array}$} & \multirow{2}{*}{$\begin{array}{c}\text { Test } \\
\text { value }\end{array}$} & \multirow{2}{*}{$\begin{array}{c}p- \\
\text { value }\end{array}$} & \multirow[t]{2}{*}{ Sig. } \\
\hline & Mean \pm SD & Range & & & \\
\hline \multicolumn{6}{|l|}{ Shape and margin: } \\
\hline Rounded & $1.19 \pm 0.51$ & $0.8-2.2$ & $4.188 \bullet \bullet$ & 0.008 & HS \\
\hline Oval & $1.17 \pm 0.27$ & $0.9-1.5$ & & & \\
\hline $\begin{array}{l}\text { Ill defined lesion } \\
\text { with Irregular margin }\end{array}$ & $0.8 \pm 0$ & $0.8-0.8$ & & & \\
\hline $\begin{array}{l}\text { Ill defined lesion } \\
\text { with speculated margin }\end{array}$ & $0.48 \pm 0.18$ & $0.4-0.8$ & & & \\
\hline $\begin{array}{l}\text { Oval with macro- } \\
\text { lobulated margin }\end{array}$ & $1.2 \pm 0.35$ & $0.8-1.4$ & & & \\
\hline Ill defined lump & $0.8 \pm 0$ & $0.8-0.8$ & & & \\
\hline
\end{tabular}

There were breast lesions (BIRADS III) with $\mathrm{ADC}$ values range 0.9-2.2 and breast lesions $\left(\mathrm{BI}_{-}\right.$ RADS IV) with ADV values range 0.4-1.6 (x10 $\mathrm{mm}^{2} / \mathrm{sec}$ ) (Table 13).

Table (13): Shows the ultrasound and mammographic BIRADS classification of the breast lesions in relation to the ADC values and histopathology.

\begin{tabular}{|c|c|c|c|c|c|}
\hline & \multicolumn{2}{|c|}{$\begin{array}{c}\text { ADC value } \\
\left(\times 10^{-3} \mathrm{~mm}^{2} / \mathrm{sec}\right)\end{array}$} & \multirow{2}{*}{$\begin{array}{c}\text { Test } \\
\text { value }\end{array}$} & \multirow{2}{*}{$\begin{array}{c}p- \\
\text { value }\end{array}$} & \multirow[t]{2}{*}{ Sig } \\
\hline & Mean $\pm \mathrm{SD}$ & Range & & & \\
\hline \multicolumn{6}{|l|}{ BIRADS: } \\
\hline III & $1.24 \pm 0.37$ & $0.9-2.2$ & $4.020 \bullet$ & 0.000 & HS \\
\hline IV & $0.75 \pm 0.29$ & $0.4-1.6$ & & & \\
\hline \multicolumn{6}{|l|}{ Histopathology: } \\
\hline Benign & $1.31 \pm 0.38$ & $0.8-2.2$ & $5.532 \bullet$ & 0.000 & HS \\
\hline Malignant & $0.72 \pm 0.19$ & $0.4-0.9$ & & & \\
\hline
\end{tabular}

$p$-value $>0.05$ : Non significant. $p$-value $<0.05$ : Significant. $p$-value $<0.01$ : Highly significant $\bullet$ : Independent $t$-test. $\bullet$ : One way ANOVA test. 
The examined breast lesions display, washout, platue and rising curve pattern (Tables 14,15).

Table (14): Shows the type of time/signal intensity in relation to the ADC values.

\begin{tabular}{llllll}
\hline & $\begin{array}{c}\text { ADC value } \\
\left(\times 10^{-3} \mathrm{~mm}^{2} / \mathrm{sec}\right)\end{array}$ & $\begin{array}{c}\text { Test } \\
\text { value }\end{array}$ & $\begin{array}{c}p- \\
\text { value }\end{array}$ & Sig. \\
\cline { 2 - 3 } & Mean $\pm \mathrm{SD}$ & Range & & & \\
\hline Curve: & & & & & \\
Washout & $0.8 \pm 0.14$ & $0.4-0.9$ & $12.669 \bullet$ & 0.000 & HS \\
Plateu & $0.76 \pm 0.37$ & $0.4-1.6$ & & & \\
Rising & $1.37 \pm 0.36$ & $0.9-2.2$ & & & \\
\hline
\end{tabular}

Sono -mammographic BIRADS classification: BIRADS 4

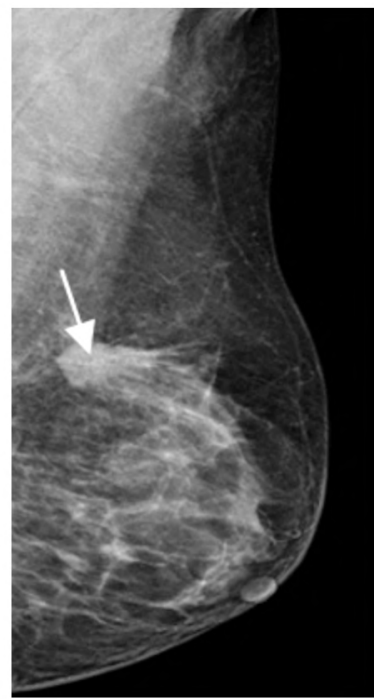

Fig. (1A): Thirty six years old female patient presented by right breast hard mass. Mammography showing left breast speculated dense lesion.

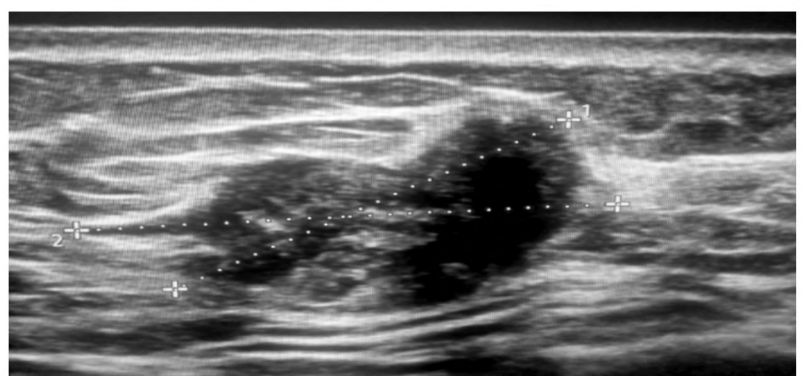

Fig. (1B): Complementary ultrasound showing left breast heterogenous hypoechoic lesion with multiple specules and surrounded by echogenic halo.
Table (15): Shows the ADC values of the breast lesions in relation to the MRI BIRADS classification and histopathology

\begin{tabular}{llllll}
\hline \multicolumn{9}{c}{$\begin{array}{c}\text { ADC value } \\
\left(\mathrm{x} 10^{-3} \mathrm{~mm}^{2} / \mathrm{sec}\right)\end{array}$} & $\begin{array}{c}\text { Test } \\
\text { value }\end{array}$ & $\begin{array}{c}p \text { - } \\
\text { value }\end{array}$ & Sig. \\
\cline { 2 - 3 } & Mean $\pm \mathrm{SD}$ & Range & & & \\
\hline BIRADS: & & & & & \\
II & $0.9 \pm 0$ & $0.9-0.9$ & $10.027 \bullet \bullet$ & 0.000 & HS \\
III & $1.42 \pm 0.34$ & $0.9-2.2$ & & & \\
IV & $0.77 \pm 0.28$ & $0.4-1.6$ & & & \\
V & $0.8 \pm 0$ & $0.8-0.8$ & & & \\
Histopathology: & & & & & \\
Benign & $1.31 \pm 0.38$ & $0.8-2.2$ & $5.532 \bullet$ & 0.000 & HS \\
Malignant & $0.72 \pm 0.19$ & $0.4-0.9$ & & & \\
\hline
\end{tabular}
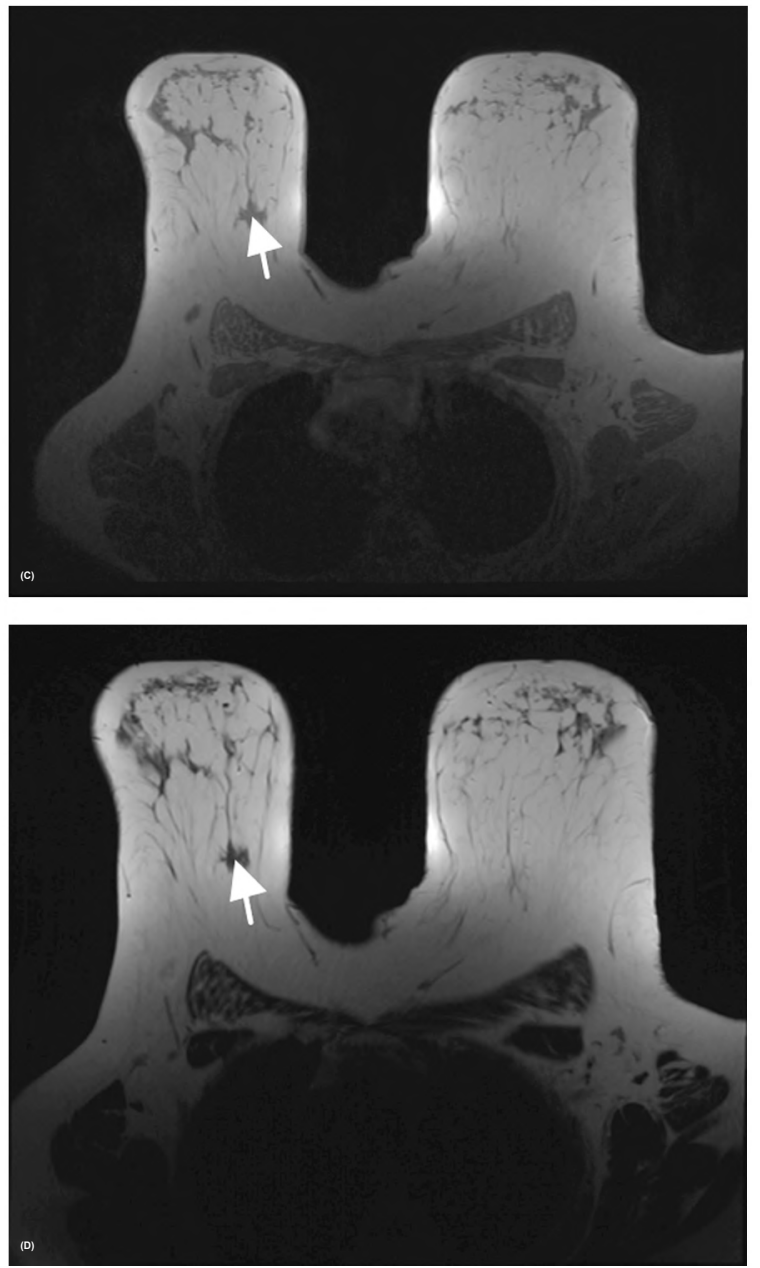

Fig. (1C,D): MRI axial images show right upper inner speculated mass with low signal in T1 and T2. 


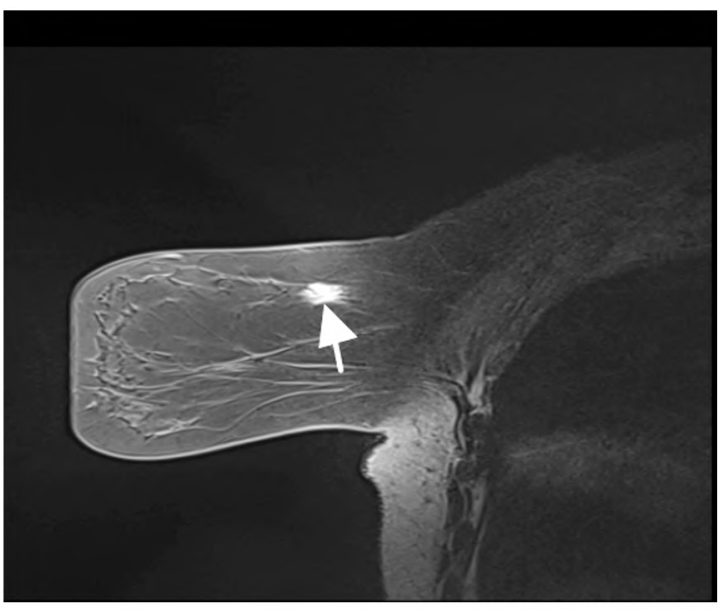

(E)

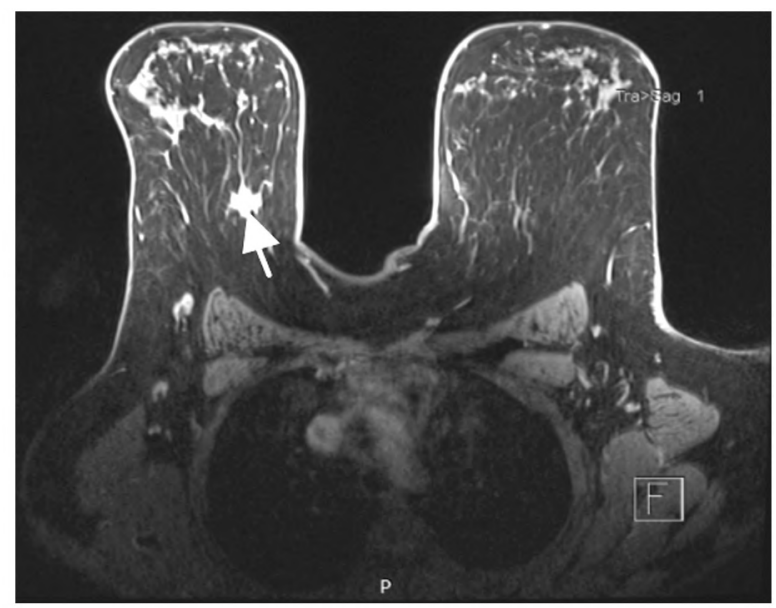

(F)

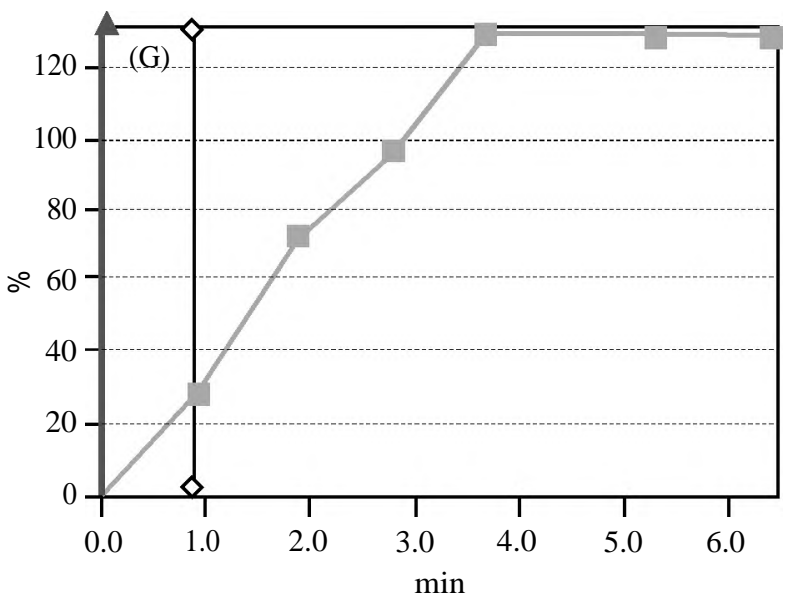

$\diamond$ Current dynamic

Reference dynamic

A Reference time

L2

Fig. (1E,F,G): MRI Sagittal and Axial (A) Dynamic THRIVE sequence. Right breast upper inner quadrant speculated lesion with homogenous contrast enhancement. (B) Time/signal intensity analysis of ROI. The mass shows plateu curve pattern (Type II) with SI \% of $130 \%$.

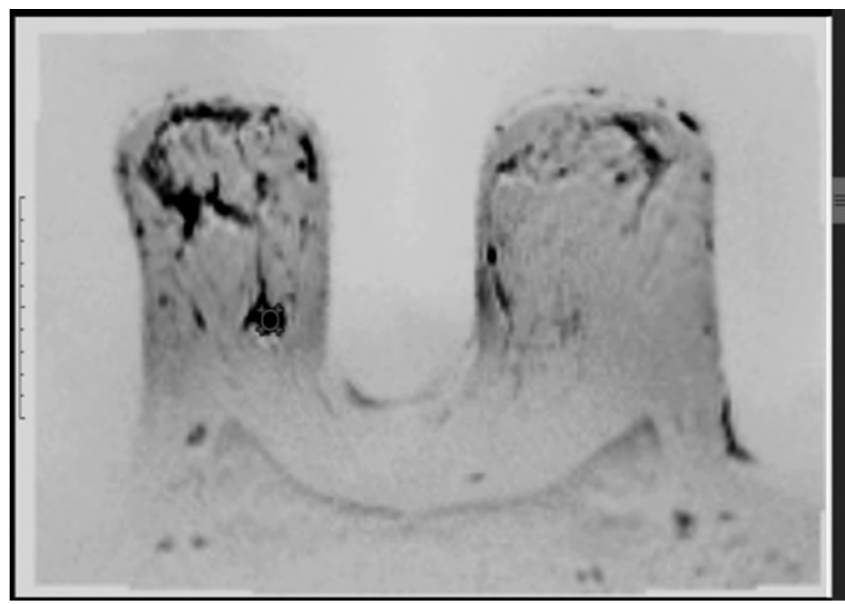

$(\mathrm{H})$

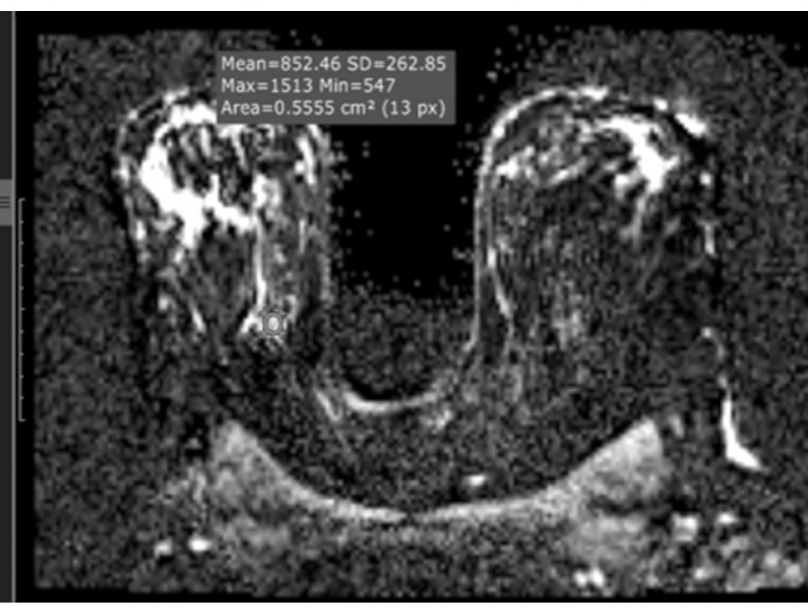

(I)

Fig. (1H,I): Post processing ADC map and diffusion sequence showing restricted diffusion of the right breast speculated mass. ADC map b 500, ADC value for ROI was $0.4 \times 10^{-3} \mathrm{~mm}^{2} / \mathrm{s}$.

Dynamic MRI BI-RADS classification: BI-RADS IV.

Pathology: Invasive duct carcinoma. 


\section{Discussion}

Breast cancer is the most common cancer in women [14]. Early diagnosis of breast cancer is important to improve prognosis. Its early detection via mammographic screening programs is the most effective approach available for reducing associated mortality [15].

Mammography and ultrasonography (US) are the primary imaging techniques for diagnosing breast cancer, followed by biopsy if a lesion is suspected of malignancy. Conventional imaging, however, suffers from limitations in the ability to detect cancer. The frequency of false-negative results at mammography is estimated to be $5-15 \%$ [16].

The sensitivity of mammography to detect breast cancer decreases in women with dense breast. This disadvantage of mammography has become more important in the recent years which have witnessed a substantial increase in the incidence of malignancy in the young women [15]

The overlap in the mammographic appearance and physical examination findings of benign and malignant lesions results in a relatively high number of benign breast biopsies, the problem of false positive mammographic findings results in unnecessary patient anxiety and morbidity related to biopsy [17].

Ultrasound has historical role as an adjunct modality to mammography in differentiating cystic from solid lesions has been widely expanded. US guided sampling procedures represent widely accepted modality in lesion evaluation. Preoperative localization under US guidance is one of the methods of choice for non palpable solid lesions. However, the main limitation of US its operator dependent nature [18].

Dynamic contrast-enhanced (DCE) MRI of the breast has been reported to improve detectability of cancer in many studies. The sensitivity is low for mammography, ultrasound or a combination of both compared with MRI [13].

Dynamic contrast-enhanced MRI of the breast has a high sensitivity for breast cancer detection and has recently been shown to be the most sensitive breast screening technique. DCE-MRI is also more accurate than mammography or ultrasound for the delineation of the extent of disease in patients with a recent diagnosis of cancer [10].

Moreover, DCE-MRI is much more expensive than other techniques and it cannot be used for patients who are contraindicated for contrast agent (e.g. patients with renal dysfunction or previous reactions to contrast agents) [19].

Techniques to improve the specificity of breast MRI could reduce unnecessary biopsies and thus improve the overall accuracy of this highly sensitive tool for detecting breast cancer [10]

Diffusion weighted MR imaging (DWI) has been reported to demonstrate usefulness in differentiating benign from malignant breast lesions [19]

Adding an ADC threshold to the breast MRI assessment increased the PPV over DCE-MRI alone and would have prevented biopsy for many benign lesions. This improvement in PPV by DWI was not found to be limited by lesion type or size [10].

In addition, using DWI and ADC values are reportedly useful in differentiating benign from malignant breast lesions and in the detection of breast cancer without administration of contrast medium. Hence, DWI could be a promising tool in screening for breast cancer without using contrast medium, especially for patients with renal dysfunction or previous reactions to contrast agents and will relieve the cost of examination [19]

This study was conducted on 30 patients with 30 breast lesions to evaluate the role of DWI as an adjunct to DCE-MRI in the probably benign and suspicious breast lesions after mammographic or ultrasonographic examinations.

Mammographic and US evaluation of the lesions was based on Breast Imaging Reporting and Data System (BI-RADS) with classification of these lesions into BI-RADS 3 and BI-RADS 4 which were our main concern in this study and were encountered in 13 and 17 lesions respectively, based on histopathology.

Dynamic contrast-enhanced MRI of the breast is increasingly used as an important tool for detecting breast cancer in high risk groups with sensitivity as high as 91-100\% [20]. The high sensitivity results primarily from the differential enhancement between normal and malignant tissue on T1-weighted imaging [10]

However, the specificity of breast DCE-MRI may be as low as 37 up to $97 \%$ [19]. This wide range of values is reflective of multiple factors including differences in magnetic field strength; imaging parameters; patient selection criteria; and perhaps most important, histologic variability of benign and malignant lesions. Contrast enhance- 
ment has been seen not only in cancer, but also in fibroadenomas, fibrocystic changes, mastitis, atypical hyperplasia and lobular neoplasia [20]

In our study, the sensitivity and specificity of DCE-MRI examination was $82.3 \%$ and $92.3 \%$ respectively, this was based on the combination of morphologic and kinetic criteria described by Kuhl [13].

There were three lesions that assigned by sonomammography as probably malignant (BIRADS 3 ); it is up and downgraded by DCI-MRI and DWI to BIRADS 4, 2 and 4.

In mass lesions, the margin and shape analysis should be performed on first post contrast image to avoid wash out and progressive enhancement of the surrounding breast tissue [21]

In our study, ill defined and spiculated margin in 11 mass lesions were found, all proved to be malignant. There were 17 well defined mass lesions, 13 of them were benign and 4 lesions were malignant.

This is comparable with Machida et al., [22] who reported that the margin description of a focal mass is the most predictive feature of the breast MR image interpretation and spiculated margins are more suspicious for carcinoma.

Internal enhancement of a focal mass is one of the most powerful diagnostic criteria for the differentiation of benign and malignant tumors [13].

Buchberger et al., [23] reported that the most frequent morphological finding among the malignant lesions was heterogeneous internal enhancement.

In our study all mass lesions that exhibited heterogeneous and ring enhancement proved to be malignant except for one lesion proved to be benign. Homogenous enhancement was found in 20 mass lesions, 11 were benign and 9 were malignant.

Two lesions of non mass like enhancement were encounted, one of them was malignant and showed diffuse heterogeneous enhancement, the other one lesion was benign and showed heterogenous and peripheral enhancement.

Imamura et al., [24] found in their study that malignant non mass lesions tended to show either segmental or branching ductal distribution, and when lesions with these patterns are considered malignant the sensitivity and specificity were $68.8 \%$ and $63.6 \%$ respectively. They also reported that using the enhancement pattern in differentiation between benign and malignant lesions was often difficult with non mass like enhancement as there was no standardized method for interpreting them.

In our study after evaluation of the morphologic characteristics of each lesion, its dynamic behavior with quantitative analysis of signal intensity [measured by means of computer manipulated region of interest (ROI)] as well as assessment of the shape of the time/signal intensity curve was done.

A overlaps in the enhancement rate of benign and malignant lesions ranged from 4.4 to $51 \%$ (in benign lesions) and from 11 to $270 \%$ (in malignant lesions) were found, these are comparable with the study of Kuhl [13] who reported that enhancement rates proved to be not diagnostically relevant because the broad overlap between benign and malignant lesions and were therefore of only limited diagnostic use in the individual patient.

In our study, the mass lesions type I curve were found in 10 pathologically proven benign lesions, type III curve was found in 9 pathologically proven malignant lesions compared to 2 pathologically proven benign lesions, and type II curve was present in 1 benign lesion compared to 8 malignant lesions.

This is comparable with many studies that reported the importance of the curve shape in differentiating between malignant and benign lesions. Zahoor [21] reported that the use of timesignal intensity curves resulted in dramatically higher specificity $(83 \%)$ than were obtained when enhancement rate specificity $(37 \%)$ was used. Type III curve is more suspicious for malignancy [25] whereas persistent curves are associated with benign lesions. Plateau curves are indicative of either malignant or benign lesions [26]

The non mass type III curve was found in 1 lesion $(100 \%)$ which proven to be malignant. In this study, the detected breast lesions were classified according to their criteria on unenhanced MRI (DWI and T2WI) to benign and malignant lesions, as described by Rotili et al., [27].

In our study all lesions were hyper intense on DWI except five lesions were hypointense. Partridge et al., [10] reported that some malignancies are isointense and not visible on DWI, suggesting that DWI may have lower sensitivity than DCEMRI for detecting breast cancer. So it is important to localize the ADC measurement on the basis of the DCE-MRI abnormality to avoid missing any cancers. 
Our findings for mass lesions showed that malignancies exhibit lower mean ADC values compared with benign lesions. The mean ADC for malignancies in our study was $0.4-0.9 \times 10^{-3} \mathrm{~mm}^{2} / \mathrm{s}$ and for benign lesions was $0.8-2.2 \times 10^{-3} \mathrm{~mm}^{2} / \mathrm{s}$.

This is comparable with Pereira et al., [28] . In their study, they found that the threshold between malignant and benign lesions for highest sensitivity and specificity (both $86 \%$ ) was around $1.13 \pm 0.10$ x $10^{-3} \mathrm{~mm}^{2} / \mathrm{s}$. For a threshold of $0.95 \pm 0.10 \times 10^{-3}$ $\mathrm{mm}^{2} / \mathrm{s}$, specificity was $100 \%$ but sensitivity was very low. So they concluded that the ADC may help to differentiate benign and malignant lesions with good specificity, and may increase the overall specificity of breast MRI.

This difference in ADC threshold can be explained by difference in the study population. Moreover, many technical variables can affect the ADC values, such as different MRI units, pulse sequences, or $b$-values [24]. There are also factors related to imaging parameters (magnetic susceptibility, spatial resolution and signal - to -noise ratio) and those related to the pathophysiologic features (cellular density and tissue component) of the lesions. In the female body, the hormonal status affects the water content and reportedly results in a 5.5\% variation in breast ADC throughout the menstrual cycle. This is a significant limitation of applying ADC values in the clinical setting [29]

In our study we calculated the ADC value with high $b$-values (600 and 1500) to avoid the signal attenuation caused by perfusion effects at low $b$ values. The ADC varies with the choice of different $b$-values. Filippi et al., [30] found that the ADC value obtained with low $b$-values $\left(0\right.$ and $\left.150 \mathrm{~s} / \mathrm{mm}^{2}\right)$ is higher than that obtained with higher $b$-values (499 and $1500 \mathrm{~s} / \mathrm{mm}^{2}$ ) for all lesions types due to contribution of mainly perfusion effects to the ADC. The diagnostic performance is not affected by the choice of the $b$-values. The results imply that to differentiate benign from malignant breast lesions.

The diffusion criteria for mass and non mass lesions were assessed. All of them were restricted except five lesions showed facilitated diffusion which proved to be benign. We agree with Partridge et al., [10] who reported that the specificity of DWI is similar for mass and non mass like enhancement.

\section{Conclusion:}

DWI improves the diagnostic accuracy of the DCE-MRI of the breast. It is a better method for detecting breast lesions than either T1- or T2- weighted imaging, but it is better to be performed in conjunction with contrast enhanced MRI. Moreover, the combination of mammography, DWI and T2WI could be useful in screening for breast cancer in patients who cannot receive contrast medium.

\section{References}

1- STACHS A., STUBERT J., REIMER T. and HARTMANN S.: Benign breast disease in women. Deutsches Ärzteblatt International, 116 (33-34): 565, 2019.

2- YADAV A.S., BUTTI R., DAS S., et al.: Receptor tyrosine kinases (RTKs) in breast cancer: Signaling, therapeutic implications and challenges. Molecular Cancer, 17 (1): $1-8,2018$

3- SHI R.Y., YAO Q.Y., WU L.M. and XU J.R.: Breast lesions: Diagnosis using diffusion weighted imaging at $1.5 \mathrm{~T}$ and 3.0 T-systematic review and meta-analysis. Clinical Breast Cancer, 18 (3): e305-20, 2018.

4- YILMAZ E., SARI O., YILMAZ A., et al.: Diffusion Weighted Imaging for the discrimination of benign and malignant breast masses; utility of ADC and relative ADC, Journal of the Benign Society of Radiology, 102 (1): 16, 2018.

5- OEFFINGER K.C., FONTHAM E.T., ETZIONI R., HERZIG A., MICHAELSON J.S., SHIH Y.C., WALTER L.C., CHURCH T.R., FLOWERS C.R., LAMONTE S.J. and WOLF A.M.: Breast cancer screening for women at average risk: 2015 guideline update from the American Cancer Society. JAMA, 314 (15): 1599-614, 2015.

6- JAVED M.U., ALEEM S., ASIF S.J. and IQBAL J.: Breast Abscess. The Professional Medical Journal, 24 (01): 8994, 2017.

7- D'ORSI C., BASSETT L. and FEIG S.: Breast imaging reporting and data system (BI-RADS). Breast imaging atlas. In Christoph I. Lee, Constance D. Lehman, Lawrence W. Bassett, (eds.), Oxford University Press, pp: 328-349, 2018.

8- FRANÇA L.K., BITENCOURT A.G., PAIVA H.L., SILVA C.B., PEREIRA N.P., PALUDO J., GRAZIANO L., GUATELLI C.S., SOUZA J.A. and MARQUES E.F.: Role of magnetic resonance imaging in the planning of breast cancer treatment strategies: Comparison with conventional imaging techniques. Radiologia Brasileira, 50: 76-81, 2017.

9- LI L., LIN L. and WANG L.V.: Multiscale photoacoustic tomography. Optics and Photonics News, 29 (4): 32-9, 2018.

10- PARTRIDGE S. and McDONALD E.: Diffusion weighted MRI of the breast: Protocol optimization, guidelines for interpretation, and potential clinical applications. Magn Reson Imaging Clin. N. Am., 21 (3): 601-624, 2013.

11- BRYNOLFSSON P., NILSSON D., TORHEIM T., et al.: Haralick texture features from apparent diffusion coefficient (ADC) MRI images depend on imaging and preprocessing parameters. Scientific Reports, 7 (1): 1-1, 2017.

12- HETTA W.: Role of diffusion weighted images combined with breast MRI in improving the detection and differentiation of breast lesions. The Egyptian Journal of Radiology and Nuclear Medicine, 46 (1): 259-70, 2015. 
13- KUHL H.: Breast cancer risk in the WHI study: The problem of obesity. Maturitas, 51 (1): 83-97, 2005.

14- LUCZYN’SKA E., HEINZE S., ADAMCZYK A., RYS J., MITUS J.W. and HENDRICK E.: Comparison of the mammography, contrast-enhanced spectral mammography and ultrasonography in a group of 116 patients. Anticancer Research, 36 (8): 4359-66, 2016.

15- FATIMA K., MASROOR I. and KHANANI S.: Probably benign solid breast lesions on ultrasound: Need for biopsy reassessed. Asian Pacific journal of cancer prevention: APJCP, 19 (12): 3467, 2018.

16- KUHL C.K., STROBEL K., BIELING H., LEUTNER C., SCHILD H.H. and SCHRADING S.: Supplemental breast MR imaging screening of women with average risk of breast cancer. Radiology, 283 (2): 361-70, 2017.

17- ISTOMIN A., MASARWAH A., OKUMA H., SUTELA A., VANNINEN R. and SUDAH M.: A multiparametric classification system for lesions detected by breast magnetic resonance imaging. European Journal of Radiology, 132: 109322,2020

18- SCHEEL J.R., PEACOCK S., OREM J., BUGEZA S., MUYINDA Z., PORTER P.L., WOOD W.C., COMIS R.L. and LEHMAN C.D.: Improving breast ultrasound interpretation in Uganda using a condensed breast imaging reporting and data system. Academic Radiology, 23 (10): 1271-7, 2016

19- YABUUCHI H., MATSUO Y., KAMITANI T., et al.: Non-mass-like enhancement on contrast-enhanced breast MR imaging: Lesion characterization using combination of dynamic contrast-enhanced and diffusion-weighted MR images. European Journal of Radiology, 75 (1): e12632, 2010.

20- ZAHOOR S., HAJI A., BATTOO A., QURIESHI M., MIR W. and SHAH M.: Sentinel lymph node biopsy in breast cancer: A clinical review and update. Journal of Breast Cancer, 20 (3): 217-27, 2017.

21- MARTAINDALE S.R.: Breast MR Imaging. Current MR Imaging of Breast Cancer, An Issue of Magnetic Resonance Imaging Clinics of North America, E-Book, 26 (2): 17990, 2018.

22- MACHIDA Y., TOZAKI M., SHIMAUCHI A. and YOSHIDA T.: Two distinct types of linear distribution in nonmass enhancement at breast MR imaging: Difference in positive predictive value between linear and branching patterns. Radiology, 276 (3): 686-94, 2015.

23- BUCHBERGER W., OBERAIGNER W., KREMSER C., GAUTSCH K. and SIEBERT U.: Non-mass Enhancement in Breast MRI: Characterization with BI-RADS Descriptors and ADC Values. Sci. Medicine Journal, 3 (2): $77-$ 87, 2021.

24- IMAMURA T., ISOMOTO I., SUEYOSHI E., et al Diagnostic performance of ADC for Non-mass-like breast lesions on MR imaging. Magnetic Resonance in Medical Sciences, 9 (4): 217-25, 2010.

25- LIU Y., ZHU L.N., LIU Q., HAN C., ZHANG X.D. and WANG X.Y.: Automatic extraction of imaging observation and assessment categories from breast magnetic resonance imaging reports with natural language processing. Chinese Medical Journal, 132 (14): 1673, 2019.

26- HA S.M., CHAE E.Y., CHA J.H., KIM H.H., SHIN H.J. and CHOI W.J.: Breast MR Imaging before surgery: Outcomes in patients with invasive lobular carcinoma by using propensity score matching. Radiology, 287 (3): 771-7, 2018.

27- ROTILI A., TRIMBOLI R.M., PENCO S., PESAPANE F., TANTRIGE P., CASSANO E. and SARDANELLI F.: Double reading of diffusion-weighted magnetic resonance imaging for breast cancer detection. Breast Cancer Research and Treatment, 180 (1): 111-20, 2020.

28- PEREIRA N.P., CURI C., OSÓRIO C.A., MARQUES E.F., MAKDISSI F.B., PINKER K. and BITENCOURT A.G.: Diffusion-weighted magnetic resonance imaging of patients with breast cancer following neoadjuvant chemotherapy provides early prediction of pathological response-a prospective study. Scientific Reports, 9 (1): $1-8,2019$

29- KIM K.W., KUZMIAK C.M., KIM Y.J., SEO J.Y., JUNG H.K. and LEE M.S.: Diagnostic usefulness of combination of diffusion-weighted imaging and T2WI, including apparent diffusion coefficient in breast lesions: Assessment of histologic grade. Academic Radiology, 25 (5): 643-52, 2018 .

30- FILIPPI M., CANU E., GASPAROTTI R., AGOSTA F. VALSECCHI P., LODOLI G., GALLUZZO A., COMI G. and SACCHETTI E.: Patterns of brain structural changes in first-contact, antipsychotic drug-naive patients with schizophrenia. American Journal of Neuroradiology, 35 (1): 30-7, 2014 


\section{دور الرثين المغناطيسى الانتشارى

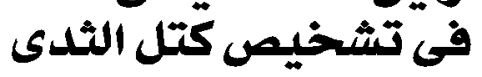

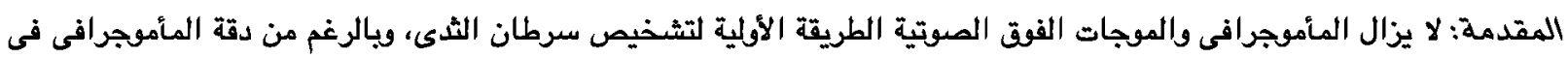

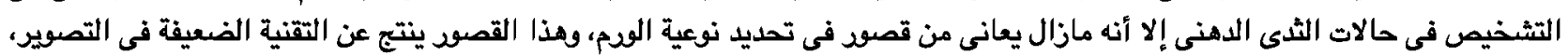

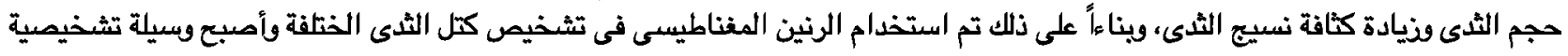

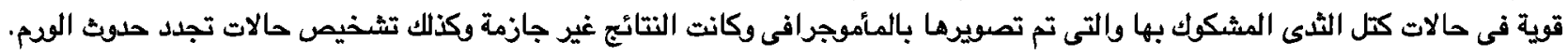
الهدف من البحث: الغرض من هذا البحث هو التاكد على أهمية دود الرنين المغناطيسى الانتشارى ومعامل الانتشار الظاهرى فى تشخيص

كتل الثدى الحميدة والضبيثة والتفرقة بينهما.

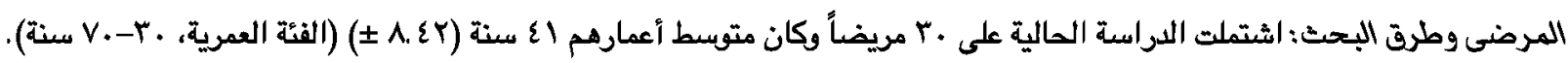

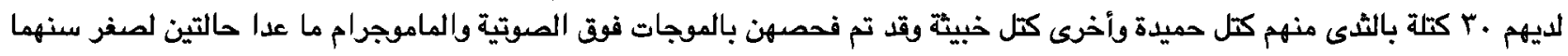

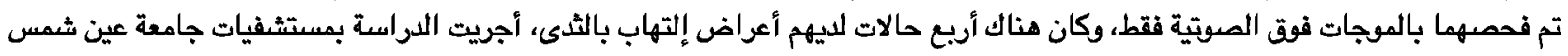

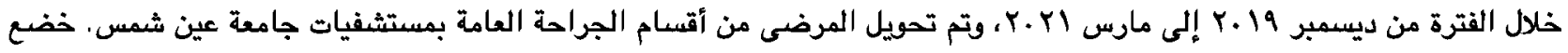

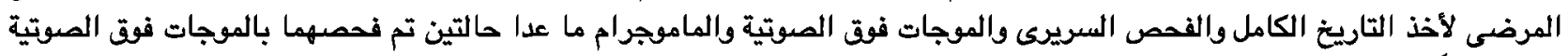

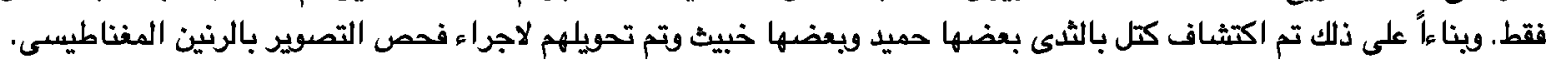

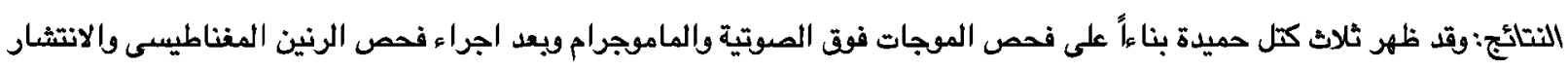

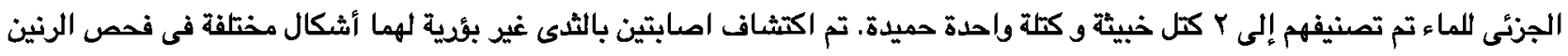

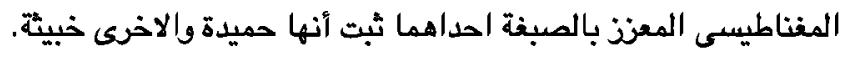

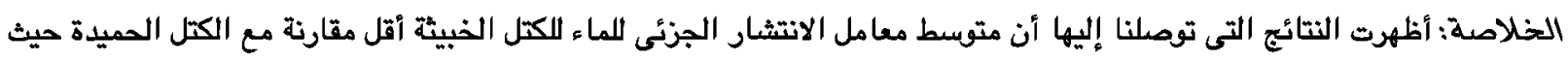

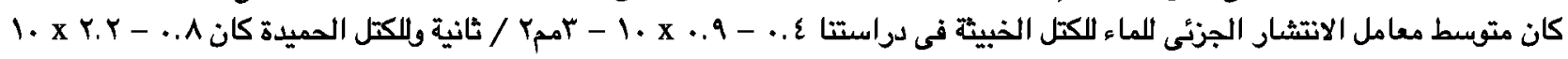
- كان مثن / ثانية. 